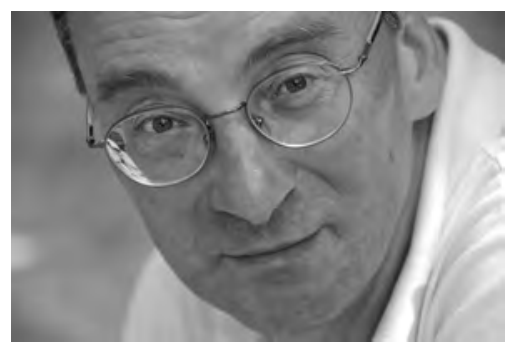

\section{Von Trägern und Erbringern}

Auch Insider der Sozialwirtschaft können gelegentlich bei der komplizierten Terminologie ins Straucheln geraten, wenn von Leistungsträgern und Kostenträgern, von Leistungserbringern und freien Trägern die Rede ist. Der allgemeine Teil des Sozialgesetzbuches listet in einem eigenen Kapitel die zahlreichen Leistungsträger auf, von der Ausbildungsförderung bis zur Rehabilitation ( $\mathbb{S} 18$ bis 29 SGB I), und weist ihnen auch ihre gesetzlichen Aufgaben detailliert zu. Da diese "Leistungsträger" die daraus resultierenden Ansprüche auf Sach- und Dienstleistungen sowie auf persönliche Hilfen im Einzelfall kaum selbst erfüllen können, treten die »Leistungserbringer « auf den Plan. Dieser im Gesundheitswesen seit längerem gängige Begriff hat sich auch in der Sozialwirtschaft durchgesetzt. Rechtlich und wirtschaftlich abgewickelt wird diese Kooperation im sozialrechtlichen Dreiecksverhältnis zwischen sozialleistungsberechtigtem Bürger, Sozialleistungsträger und Leistungserbringer. Noch bildet die Zusammenarbeit zwischen den beiden Letzteren die ökonomische Basis vieler sozialer Organisationen und Unternehmen in der Sozialwirtschaft. Dass es sich für diese deshalb lohnt, über eine Optimierung ihres »Zuweiser-Managements« nachzudenken, erläutert ein Beitrag in diesem Heft.

Vor einem Jahr haben wir dieser Zeitschrift eine neue Heftstruktur gegeben mit mehr Themen und festen Rubriken. Diese Neuerungen und das runderneuerte Layout sind bei vielen Leserinnen und Lesern gut angekommen. In dieser Ausgabe präsentieren wir Ihnen nun in der Heftmitte im Gesamtverzeichnis alle Beiträge des letzten Jahres - zum Nachschlagen und zum Entdecken von Beiträgen, die immer noch lesenswert sind!

Gerhard Pfannendörfer, Chefredaktion E-Mail pfannendoerfer@nomos.de 